\title{
Targeting colorectal cancer stem cells with inducible caspase-9
}

\author{
Kristel Kemper · Hans Rodermond • \\ Selçuk Colak $\cdot$ Catarina Grandela • \\ Jan Paul Medema
}

Published online: 6 January 2012

(c) The Author(s) 2012. This article is published with open access at Springerlink.com

\begin{abstract}
Colorectal cancer stem cells (CSCs) drive tumor growth and are suggested to initiate distant metastases. Moreover, colon CSCs are reportedly more resistant to conventional chemotherapy, which is in part due to upregulation of anti-apoptotic Bcl-2 family members. To determine whether we could circumvent this apoptotic blockade, we made use of an inducible active caspase-9 (iCasp9) construct to target CSCs. Dimerization of iCasp9 with AP20187 in HCT116 colorectal cancer cells resulted in massive and rapid induction of apoptosis. In contrast to fluorouracil (5-FU)-induced apoptosis, iCasp9-induced apoptosis was independent of the mitochondrial pathway as evidenced by Bax/Bak double deficient HCT116 cells. Dimerizer treatment of colon CSCs transduced with iCasp9 (CSC-iCasp9) also rapidly induced high levels of apoptosis, while these cells were unresponsive to $5-\mathrm{FU}$ in vitro. More importantly, injection of the dimerizer into mice that developed a colon CSC-iCasp9-induced tumor resulted in a strong decrease in tumor size, an increase in tumor cell apoptosis and a clear loss of CD133 ${ }^{+}$CSCs. Taken together, our data indicate that dimerization of iCasp9 circumvents the apoptosis block in CSCs, which results in effective tumor regression in vivo.
\end{abstract}

Keywords Cancer stem cell · Inducible caspase-9 . Therapy $\cdot$ Resistence

K. Kemper · H. Rodermond · S. Colak · C. Grandela

J. P. Medema ( $\square)$

Laboratory for Experimental Oncology and Radiobiology,

Centre for Molecular Medicine, Academic Medical Centre,

Meibergdreef 9, 1105 AZ Amsterdam, The Netherlands

e-mail: j.p.medema@amc.uva.nl

\section{Introduction}

Cancer stem cells (CSCs), also called tumor-initiating cells, were first identified in haematological malignancies, but more recently these cells were also described in solid tumors, like colorectal cancer (CRC) [1-4]. CSCs are a subpopulation of cells within the tumor that contain selfrenewal capacity and the ability to differentiate. Therefore, they are thought to be the driving force behind tumor growth and metastasis. In vitro experiments have shown that colon CSCs are more resistant to treatment with fluorouracil (5-FU) and oxaliplatin compared to their more differentiated progeny $[3,5]$ and therefore, CSCs are thought to be responsible for tumor recurrence after treatment.

Chemoresistance of tumor cells can be caused by alterations in the expression of apoptotic and anti-apoptotic genes [3]. Apoptosis can be triggered by the extrinsic pathway, initiated by ligation of death receptors on the cell surface leading to caspase- 8 activation, or by the intrinsic pathway, which leads to cytochrome $c$ release from the mitochondria [6]. Release of cytochrome $c$ is regulated by Bax and Bak-dependent mitochondrial permeabilization and is counteracted by the anti-apoptotic Bcl-2 family members. Cytochrome $c$ release is a crucial step in the assembly of the apoptosome, which in effect results in caspase-9 activation through induced proximity and subsequently cumulates in proteolytic cleavage and thereby activation of the downstream executioner caspases3 and -7.

Evasion of apoptosis is one of the hallmarks of cancer [7]. Resistance to chemotherapy-induced apoptosis in CRC tumors is in part due to upregulation of anti-apoptotic molecules and downregulation of pro-apoptotic molecules. For instance, the expression level of anti-apoptotic molecule 
Bcl-2 has been reported to increase during the early stages of colorectal tumorigenesis [8]. On the other hand, pro-apoptotic molecules like Bax and Bak [9] are decreased in CRC tumors. Low levels of pro-apoptotic molecule Bax have been shown to correlate to 5-FU resistance [10]. In addition, more than $50 \%$ of colon tumors with defects in mismatch repair harbor mutations in Bax, thereby compromising its function in apoptosis [11]. CRCs therefore appear to escape from therapyinduced apoptosis by changes in the expression of apoptosis-regulatory genes.

Unlike executioner caspases, such as caspase-3, that are activated by cleavage, caspase- 9 undergoes a conformational change when two caspase- 9 molecules are brought into close proximity. This opens up the catalytic site and unleashes the proteolytic activity. Based on the same principle an inducible system has been developed where the catalytic domain of caspase- 9 is fused to a modified FK506-binding domain (FKBP) that can be homodimerized by addition of an optimized chemical inducer of dimerization (CID) AP20187 [12]. The dimerizer is membrane-permeable and binds at subnanomolar concentrations to the modified FKBP, while the affinity for the endogenous FKBP is 1,000-fold lower. Therefore addition of the dimerizer brings two inducible caspase-9 (iCasp9) molecules into close proximity and thereby rapidly activates downstream executioner caspases in a cytochrome $c$-independent fashion. In contrast to other inducible suicide systems, such as the HSV-1-derived thymidine kinase (HSV-TK)/ganciclovir (GCV) method, the mode of action of iCasp9 does not rely on proliferation, which makes it ideal to target CSCs, as these have been shown under certain conditions to be quiescent or slow cycling [13-16]. In addition, HSV-TK has been shown to induce a bystander effect, since the prodrug GCV, when converted to its active form by HSV-TK, can spread to other cells and also exert its inhibitory function in cells that do not express HSV-TK. In contrast, iCasp9-induced apoptosis is cell autonomous and a more reliable method to selectively target individual cells without collateral damage. Lastly, since caspase-9 is downstream of the mitochondria the sensitivity of cells to its activation should be independent of the Bcl-2 family of proteins.

The iCasp9 construct has been tested in an in vitro and in vivo xenograft model for prostate cancer [17], but the cytotoxic effect on CSCs was not taken into consideration in this study. Since CSCs are known to be resistant to conventional therapy, we decided to study the effect of dimerization of iCasp9 in these cells. We show here that CRC cells that have lost pro-apoptotic proteins are still responsive to the dimerization of iCasp9. More importantly, colon CSCs are very effectively killed by dimerization of iCasp9 both in vitro and in vivo.

\section{Materials and methods}

Cell lines, culture, vectors, transduction, selection and dimerizer treatment

HCT116 lines were derived from Dr. G. C. Chinnadurai (St. Louis University School of Medicine, USA) and cultured in Dulbecco's Modified Eagle Medium (DMEM, Invitrogen) containing $8 \%$ fetal calf serum (FCS), $2 \mathrm{mM}$ glutamine, $100 \mathrm{U} / \mathrm{ml}$ penicillin and $100 \mu \mathrm{g} / \mathrm{ml}$ streptomycin. The CSC line, obtained from a primary carcinoma under standard medical ethical procedures of the Academic Medical Center was derived and cultured as described previously [3]. PMX-iCasp9-IRES-GFP and pMX-IRESYFP virus were produced in Phoenix cells and virus was harvested after $48 \mathrm{~h}$. Transduction was performed overnight with addition of $10 \mu \mathrm{g} / \mathrm{ml}$ polybrene. Transduced cells were selected by sorting for GFP/YFP expression. Treatment was performed with $10 \mathrm{nM}$ dimerizer AP20187 obtained from ARIAD Pharmaceuticals (Cambridge, MA, USA) or $500 \mu \mathrm{g} / \mathrm{ml} 5$-FU.

FACS analysis, active caspase-3 assay, Annexin-V staining and limiting dilution assay (LDA)

Cell death was analyzed by FACS using PI-positivity (200 ng/ml) and apoptosis was analyzed by DNA fragmentation using a Nicoletti assay. To this end cells were incubated overnight in Nicoletti buffer $(0.1 \%$ Na-citrate, $0.1 \%$ Triton-X-100 and $50 \mu \mathrm{g} / \mathrm{ml} \mathrm{PI}$ in $\mathrm{H}_{2} 0$ ) and analyzed the next day. Activity of caspase-3 was analyzed by CaspGLOW Red Active Caspase-3 Staining Kit (K193100, Biovision) according to manufacturer's protocol. Cells were stained for CD133 (AC133, Miltenyi) to identify the CSC fraction. Early apoptosis was analyzed by Annexin-V staining (550474, BD Biosciences). Xenografts were dissociated with $1.5 \mathrm{mg} / \mathrm{ml}$ of collagenase II (C6885, Sigma) and $20 \mu \mathrm{g} / \mathrm{ml}$ of hyaluronidase (H4272, Sigma) at $37^{\circ} \mathrm{C}$ for 30 min. Cells were then stained in PBA (PBS with $1 \%$ BSA and $0.02 \%$ sodium azide) for PE-anti-Epcam (EBA-1, BD Biosciences) and APC-anti-CD133 (AC133, Miltenyi). All analyses were performed on the FACS Canto (BD Biosciences), while further analyses were performed in FlowJo (BD Biosciences). For LDA, cells were deposited by FACSAria in a 96-well plate as 1, 2, 4, 8, 10, 12, 16, 20 and 24 cells per well in at least 8 wells per condition. After two weeks, the presence of spheroids in each well was scored.

Cell lyses, western blotting and antibodies

Cells were lysed in Triton-X-100 lysis buffer (20 mM Tris $\mathrm{HCl}$, pH 7.4, 137 mM NaCl, 10\% Glycerin, 1\% Triton-X-100, 
$2 \mathrm{mM}$ EDTA, $2 \mu \mathrm{g} / \mathrm{ml}$ Aprotinin, $10 \mu \mathrm{g} / \mathrm{ml}$ Leupeptin). Protein amounts were measured by BCA protein assay (Thermo Scientific Pierce) according to the manufacturer's protocol. Per lane, $20 \mu \mathrm{g}$ protein was loaded on $12 \%$ acryl amide gels and blotted onto nitrocellulose membrane. Unspecific binding was blocked in blocking buffer (LICOR). Membranes were incubated overnight at $4{ }^{\circ} \mathrm{C}$ with rabbit-anti-cleaved caspase 3 (9661, Cell Signaling), rabbit-anti-PARP (9542, Cell Signaling) or mouse-antibeta I tubulin (T7816, Sigma). After washing in PBS-0.2\% Tween, membranes were incubated for $1 \mathrm{~h}$ at RT with IRDye 680 -anti-rabbit IgG (LICOR) or IRDye 800 antimouse IgG (LICOR). Membranes were developed with the Odyssey (LICOR).

\section{In vivo tumor growth}

All animal experimentation was approved by the Dier Experimentele Commissie (DEC) of the institute. C002iCasp9-IRES-GFP cells were injected subcutaneously in male athymic Balb/cOlaHsd-Foxn $1^{n u}$ mice (Harlan). In the first experiment, when tumors reached an average size of $200 \mathrm{~mm}^{3}$, the mice were treated with either one (day 0 ) or two intraperitonial injections (day 0,2 ) of $1 \mathrm{mg} / \mathrm{kg}$ AP20187 dissolved 4\% ethanol, 10\% PEG-400 and 86\% PBS-2\%Tween. In the second experiment, treatment was either started at the same day of the injection of the tumor cells or after the tumors reached an average size of $200 \mathrm{~mm}^{3}$. Mice were treated every day with $0.5 \mathrm{mg} / \mathrm{kg}$ (intervention) or $1 \mathrm{mg} / \mathrm{kg}$ (therapeutic) AP20187 for 5 consecutive days. Tumor size was measured twice a week by caliper.

\section{Immunohistochemistry and antibodies}

Tumors were fixed in paraformaldehyde overnight and embedded in paraffin. Slides were cut, deparaffinized and rehydrated. Endogenous peroxidase was blocked in methanol with $0.3 \% \mathrm{H}_{2} \mathrm{O}_{2}$ for $20 \mathrm{~min}$. Antigen retrieval was performed by boiling the slides in antigen unmasking buffer (H-3300, Vector Brunschwig) for $10 \mathrm{~min}$. Biotinblocking was performed with the avidin/biotin blocking kit (00-4303, Zymed). Slides were blocked with $10 \%$ FCS in PBS, and then incubated overnight at $4{ }^{\circ} \mathrm{C}$ with rabbit-antiKi67 (SP6, Neomarkers), rabbit-anti-FKBP12 (PA1-026A, Affinity Bioreagent) or mouse-anti-cytodeath (M30, Peviva). After washing, the slides were incubated for $1 \mathrm{~h}$ at RT with biotin-anti-mouse IgG (62-6540, Zymed) or biotin-anti-rabbit (E0432, Dako). After washing, the slides were incubated with AB Complex/HRP (K0355, Dako) and subsequently stained with DAB (K3468, Dako). Counterstain was performed with hematoxyline. Sides were dehydrated and mounted with perpex.

\section{Results}

Apoptosis induction by dimerization of iCasp9 is independent of Bax/Bak and XIAP

Tumor cells that are resistant to conventional chemotherapy, often downregulate pro-apoptotic molecules and/or upregulate anti-apoptotic molecules to achieve this resistance. To mimic this, we made use of the CRC cell line HCT116 deficient for both Bax and Bak [18, 19], referred to as DKO cells. Bax and Bak are required for cytochrome $c$ release from the mitochondria and thus subsequent caspase activation [20-22]. Loss of only one of the proapoptotic Bcl-2 family members does not prevent apoptosis in most cases as Bax and Bak are redundant [23, 24]. However, absence of both Bax and Bak makes cells highly resistant to mitochondrial-dependent caspase activation after exposure to various stress stimuli and chemotherapeutic insults $[22,25]$. One such stimulus is 5-FU, a pyrimidine analogue that upon cell entry is converted into different cytotoxic metabolites and incorporated into the DNA and RNA, thereby inducing cell cycle arrest and apoptosis. In agreement, treatment of WT HCT116-GFP cells with $500 \mu \mathrm{g} / \mathrm{ml} \mathrm{5-FU}$ for $24 \mathrm{~h}$ induced cell death as measured by $\mathrm{PI}^{+}$cells. This coincides with the induction of apoptosis using either DNA fragmentation or cleavage of PARP and caspase-3 as read-out (Fig. 1a-c). In contrast, 5-FU treatment of the DKO HCT116-GFP cells did not induce any signs of cell death or apoptosis (Fig. 1a-c), confirming that loss of Bax and Bak causes resistance to apoptosis induced by 5 -FU.

Next, we set out to test whether the iCasp9 construct would induce apoptosis in the mitochondrial pathwaydeficient DKO cells. To this end, we transduced WT HCT116 and the DKO cells with a vector encoding iCasp9IRES-GFP. Treatment with $10 \mathrm{nM}$ of AP20187 dimerizer resulted in a time-dependent reduction of $\mathrm{GFP}^{+}$cells and a concomitant increase in $\mathrm{PI}^{+}$cells after $24 \mathrm{~h}$, showing that cell death is induced by dimerization (Fig. 1d, e). Only the iCasp9-IRES-GFP expressing cells die upon addition of dimerizer, while control transduced (PMX-YFP) showed no response to treatment, indicating that the cytotoxic effect is dependent on the presence of iCasp9. To directly show that the cell death is a result of apoptosis, we determined the effect of dimerizer on caspase-3 activation and DNA fragmentation. This revealed that the addition of dimerizer results in an extremely rapid onset of apoptosis. Both caspase- 3 activation and DNA fragmentation were detected already after $1 \mathrm{~h}$ of dimerizer treatment, and PARP was even fully processed at this time point (Fig. 1f, g). Importantly, at the later time points tumor cells were completely disintegrated and we even failed to isolate sufficient amounts of protein from these dead cells as 

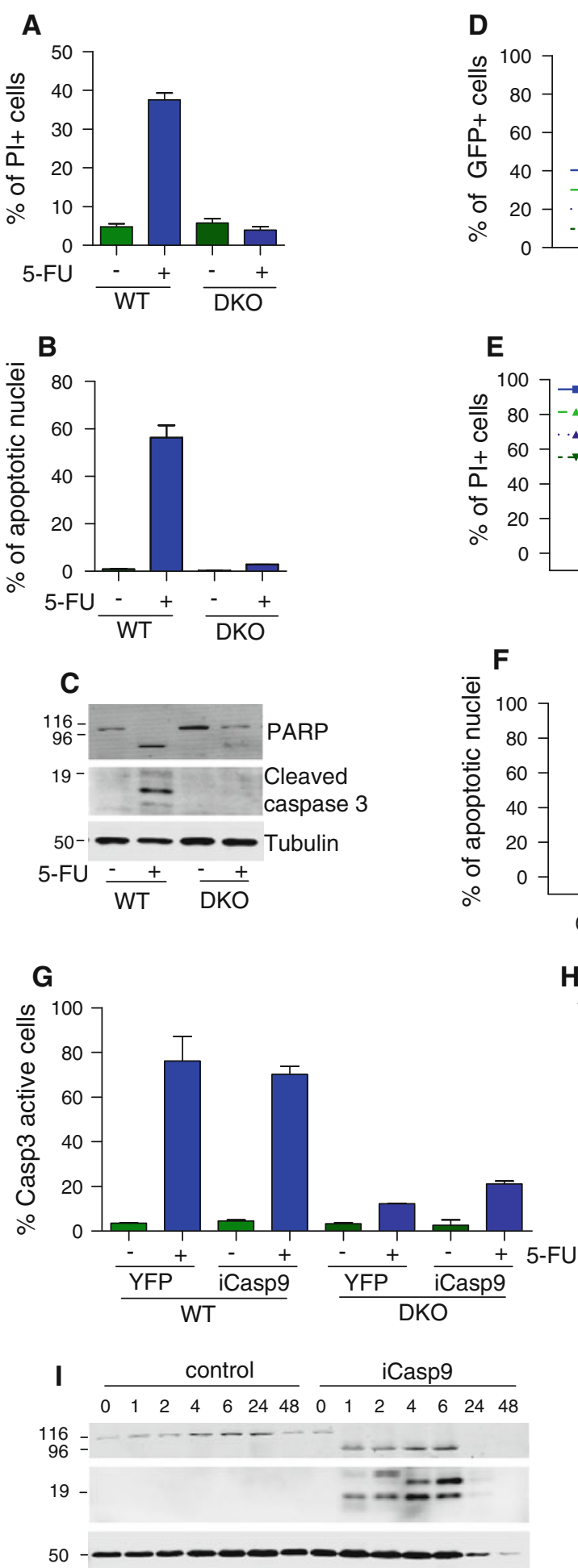

Fig. 1 Apoptosis induction by dimerization of iCasp9 is independent of Bax/Bak and XIAP. a-c HCT116 control cells and HCT116 cells deficient for Bax and knockdown for Bak (DKO) were treated with $500 \mu \mathrm{g} / \mathrm{ml} 5$-FU for $24 \mathrm{~h}$, after which they were analyzed by FACS for PI-exclusion (a), apoptotic nuclei (b), and by western for cleaved caspase 3 and cleaved PARP (c). Tubulin was used as a loading control. d-f WT HCT116 and DKO HCT116 cells were transduced with either pMX-iCasp9-IRES-GFP or control vector pMX-IRES-YFP

H
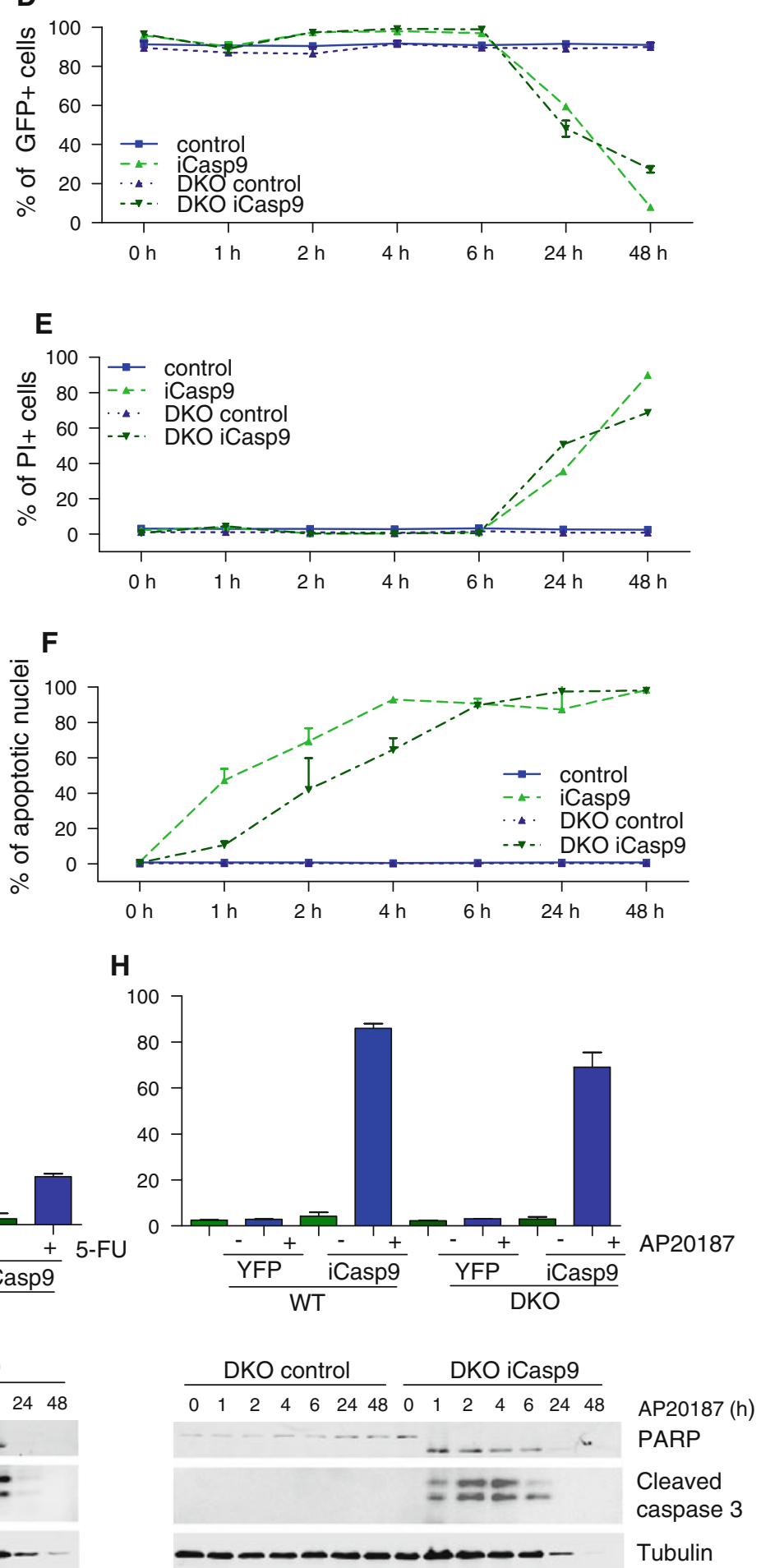

after which they were treated with $10 \mathrm{nM}$ of dimerizer AP20187 for different time points, cells were analyzed by FACS for GFP-positivity (d), PI-exclusion (e) and apoptotic nuclei (f). WT HCT116 and DKO HCT116 cells iCasp9-IRES-GFP or pMX-IRES-YFP were analysed for $\mathbf{g}$ 5-FU and $\mathbf{h}$ dimerizer-induced caspase-3 activity after 16 and $1 \mathrm{~h}$, respectively or $\mathbf{i}$ by western for cleaved caspase 3 and cleaved PARP after dimerizer treatment at different time points. Tubulin was used as a loading control 
evidenced by the lack of tubulin in the samples. As expected, the induction of apoptosis is dependent on the presence of iCasp9 and not observed in HCT116 cells transduced with a control vector.

Interestingly, when DKO HCT116 cells, transduced with iCasp9, were treated with dimerizer, they responded in a similar way as the WT HCT116 cells. Also, these DKO cells displayed a quick apoptotic response to the dimerizer, while they resist 5-FU. The dimerizer induced quick DNA fragmentation, PARP and caspase-3 cleavage (Fig. 1f, g, i). In addition, the increase in $\mathrm{PI}^{+}$cells (Fig. 1e) and decrease in $\mathrm{GFP}^{+}$cells (Fig. 1d) was found after $24 \mathrm{~h}$, indicating that dimerization of iCasp9 can induce a robust and efficient cell death, even when Bax and Bak are not present.

Taken together, the current data indicate that dimerizerinduced cell death is dependent on the presence of the iCasp9 construct, but the effectiveness does not depend on upstream signalling molecules in the apoptosis pathway like Bax and Bak.

Dimerization of iCasp9 in CSCs induces apoptosis in vitro

Since CSCs are thought to be the cells within a tumor that are resistant to conventional therapy, we switched to a more relevant in vitro system, namely that of primary spheroid culture, to test our iCasp9 construct. A CSC spheroid culture, derived from a primary CRC [4], was transduced with the pMX-iCasp9-IRES-GFP construct and subsequently single-cell cloned to avoid cell-to-cell variation in integration site or number of the retroviral vector. Two clones were used for further studies and initially treated with $10 \mathrm{nM}$ of dimerizer AP20187 for different periods of time. Also in these CSC cultures, loss of $\mathrm{GFP}^{+}$ cells and induction of $\mathrm{PI}^{+}$cells was clearly observed starting $24 \mathrm{~h}$ after treatment, indicating that cell death was induced. Similarly to the situation in HCT116 cells, rapid and robust induction of apoptosis as measured by DNA fragmentation, PARP and caspase-3 cleavage was found already after $1 \mathrm{~h}$ of treatment (Fig. 2a-d).

As these spheroid cultures do not only contain CSCs, but also more differentiated cells, as shown previously by our group [26], we decided to compare the effect of dimerization of iCasp9 to treatment with 5-FU in a more specific test that allows to discriminate CSCs from their differentiated progeny. This assay allows us to specifically analyse apoptosis induction within the CSC population and compare it directly to the more differentiated tumor progeny. To this end, we stained spheroid cultures for the CSC marker CD133 [1-3] and analyzed the activity of caspase-3 in CD133 ${ }^{\text {high }}$ (i.e. CSCs) versus CD133 ${ }^{\text {low }}$ cells (i.e. more differentiated tumor cells). In addition, as a supplement measurement for apoptosis we studied the expression of the early apoptosis marker Annexin-V. Treatment of CSCs for $48 \mathrm{~h}$ with $500 \mu \mathrm{g} / \mathrm{ml} \mathrm{5-FU}$ induced apoptosis in the more differentiated cells, whereas the CD133 ${ }^{\text {high }}$ CSCs were resistant (Fig. 2e, f). In contrast, treatment for $1 \mathrm{~h}$ with dimerizer induced apoptosis in both the CD133 ${ }^{\text {high }}$ and the CD133 ${ }^{\text {low }}$ population (Fig. 2e, f), indicating that CSCs which are normally resistant to conventional therapy can be targeted by dimerization of iCasp9.

To functionally prove that CSCs are killed by dimerization of iCasp9, we analysed the clonogenic capacity of CSCs after dimerization treatment by performing a limiting dilution assay (LDA). This assay determines the clonogenic growth of single cells derived from the spheroid cultures and is a measure for the viability of the CSCs. Spheroid cells were either pre-treated for $1 \mathrm{~h}$ with dimerizer or left untreated and subsequently deposited by FACS in a limiting dilution fashion. After 2 weeks, outgrowth of spheroids was scored. Untreated CSCs had a clonogenic capacity of approximately 1 in every 7 cells. However, pretreatment of CSC with dimerizer, resulted in a dramatic decrease in clonogenicity to only 1 in every 400 cells (clone \#1) or even a complete absence of spheroids after two weeks (clone \#2) (Fig. 2g, h). Of note, the spheroids that did grow out after dimerization treatment were all $\mathrm{GFP}^{-}$, suggesting that they had lost the construct and thereby were rendered resistant to the induction of apoptosis. Altogether, these data show that CSCs, marked by CD133, display resistance to 5-FU treatment in vitro, while dimerization of iCasp9 also induces apoptosis in the CSC fraction and thereby loss of clonogenicity.

Dimerization of iCasp9 induces apoptosis and growth delay in vivo

To test the in vivo efficacy of the iCasp9-induced CSC apoptosis, the CSC-iCasp9-IRES-GFP cells were injected subcutaneously in immunodeficient mice and allowed to grow. When tumors had reached a size of $\sim 200 \mathrm{~mm}^{3}$, mice were treated either once or twice with $1 \mathrm{mg} / \mathrm{kg}$ AP20187 intraperitoneally or left untreated. Treatment led in both cases to a reduction in tumor size for around 15 days, especially when compared to the untreated control. However, after this initial reduction, tumors started to grow out again. To determine whether regrowth was due to an escape from therapy due to the availability of the dimerizer or a simple silencing of the iCasp9 construct, we retreated the mice for a second time with dimerizer and observed a reduction in tumor size. This indicates that the iCasp9 is still present in a fraction of the tumor cells, yet we also observed a more rapid regrowth (Fig. 3a).

$\mathrm{H} \& \mathrm{E}$ staining of the treated tumors revealed that dimerization of iCasp9 induced a massive loss of cells in the tumor, which was caused by cell death, as shown by the 


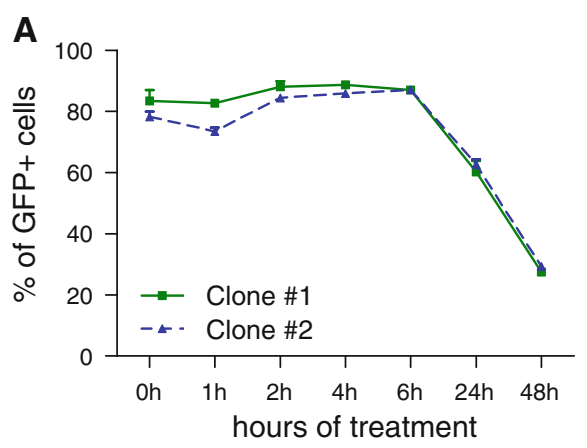

B

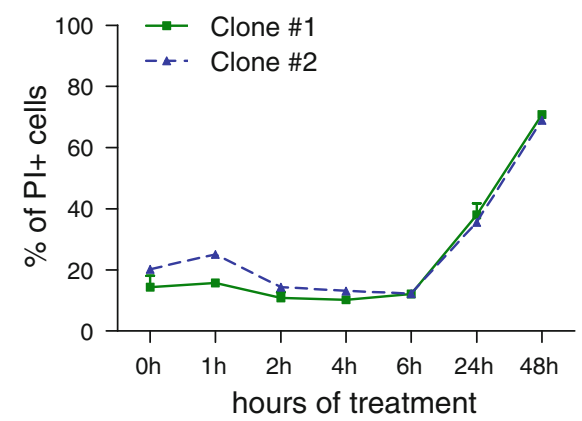

C

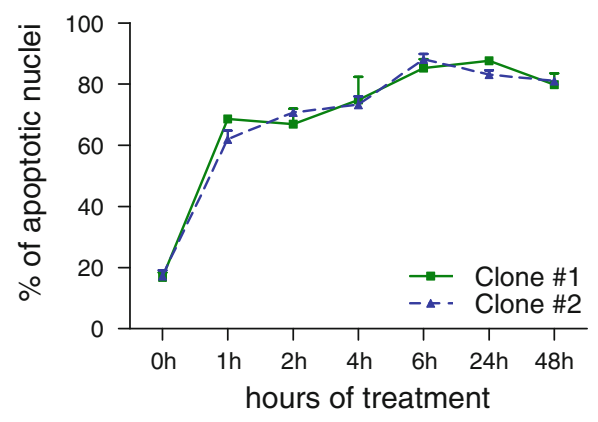

$E$
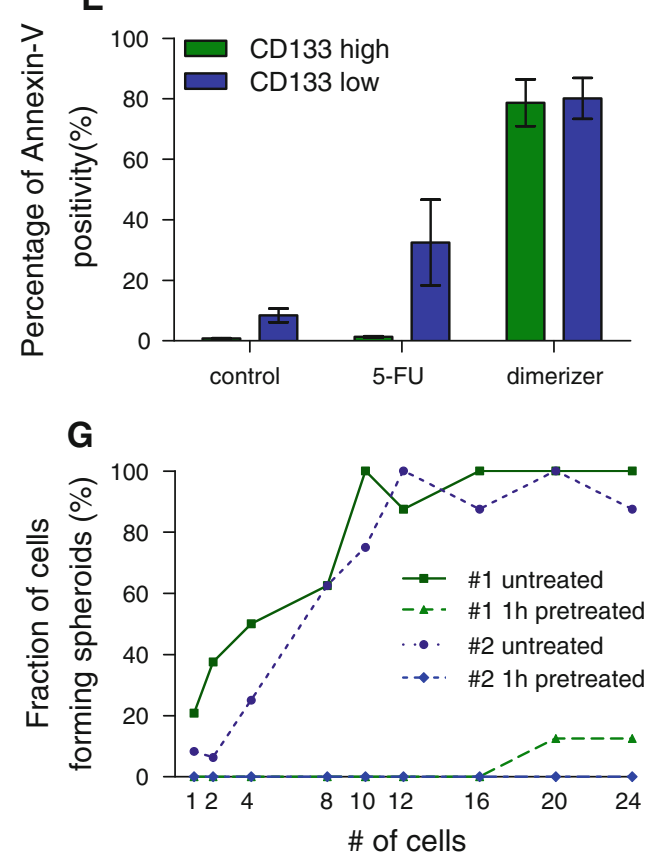

Fig. 2 Dimerization of iCasp9 induces apoptosis in CSCs in vitro. a-d Spheroid culture derived from a primary colon carcinoma was transduced with pMX-iCasp9-IRES-GFP and single-cell cloned by FACS. Two clones were treated with $10 \mathrm{nM}$ dimerizer AP20187 for different time points. Cells were analyzed by FACS for GFPpositivity (a), PI-exclusion (b), apoptotic nuclei (c) and by western for cleaved caspase 3 and cleaved PARP (d). Tubulin was used as a loading control. e, f CSCs with iCasp9 cells were treated for $48 \mathrm{~h}$ with

apoptotic cytodeath (M30) staining. Staining for proliferation marker Ki67 shows that cells that do survive the treatment are still highly proliferating, explaining the rapid
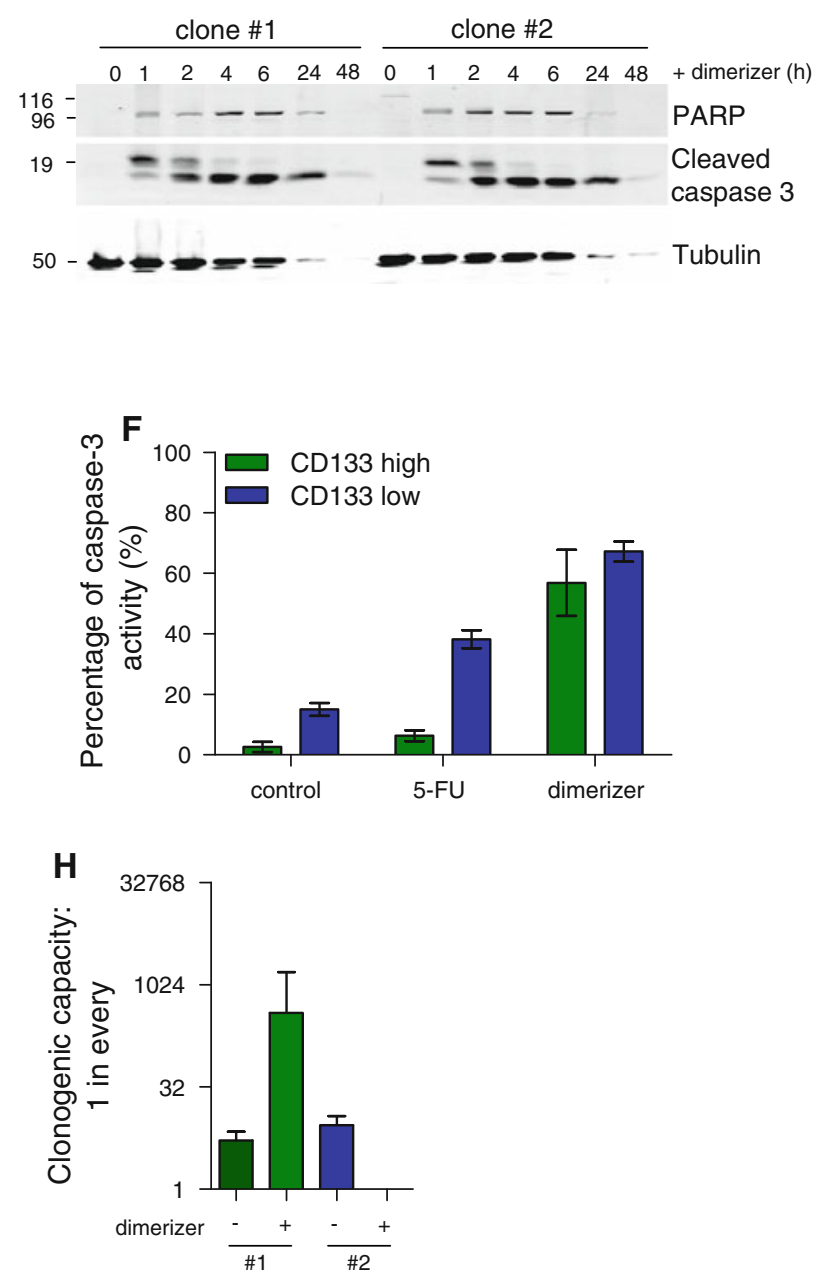

$500 \mu \mathrm{g} / \mathrm{ml} 5$-FU or for $1 \mathrm{~h}$ with $10 \mathrm{nM}$ dimerizer. Next, early markers of apoptosis, Annexin-V staining (e) and activity of caspase-3 were measured (f). $\mathbf{g}, \mathbf{h}$ The clonogenic capacity of the C002-iCasp9 after dimerizer treatment was analyzed by LDA, showing that CSCs are not resistant to apoptosis induction by dimerization of iCasp9. The graphs represent either the outgrowth of spheroids (g) or the clonogenic fraction calculated by ELDA (h)

re-growth of the tumors (Fig. 3b). When tumor cells were analyzed by FACS $48 \mathrm{~h}$ after the last treatment, a two- to fourfold relative decrease in epithelial cells was found, 
indicating that the tumor cells with iCasp9 were indeed targeted. In addition, a significant loss of GFP-positivity was observed. This confirms our observations with the second treatment of dimerizer and suggests that the iCasp9 construct in the remaining epithelial cells is either lost or inactivated. In addition, loss of expression of CSC marker CD133 was found, indicating that the CSCs were indeed targeted (Fig. 3c, d).

The in vivo experiment showed that treating tumors carrying the iCasp9 construct with dimerizer could effectively reduce tumor size, but eventually tumors will grow out again. To determine if in vivo resistance was the cause for re-growth of the tumor, we injected CSCs-iCasp9IRES-GFP subcutaneously in mice and subsequently treated the mice for 5 consecutive days with dimerizer either directly upon tumor injection or after the tumor reached $200 \mathrm{~mm}^{3}$ (Fig. 3e). This extended treatment of the mice after tumor formation induced a better and longer reduction in tumor size and. Moreover, although the tumors eventually did grow out, this occurred with slower kinetics as compared to the original line or the one-time treated mice. In contrast, direct treatment with dimerizer after tumor injection severely inhibited tumor growth. Only 1 in 4 mice developed a tumor after 10 weeks, which displayed remarkably slower growth rates than the untreated tumors. In addition, this tumor did not show any $\mathrm{GFP}^{+}$cells (Fig. 3f), indicating that the iCasp9 construct was lost.

\section{Discussion}

We have shown that iCasp9, after chemical dimerization, can induce apoptosis in cells that are resistant to conventional therapy. First of all, cells that lack expression of Bax and Bak show no apoptotic response to 5-FU treatment, whereas, as expected, dimerization of iCasp9 induces rapid induction of cell death independent of the presence of Bax and Bak. Secondly, CSCs, known to be resistant for conventional therapy $[3,5,27]$, undergo rapid apoptosis when exposed to dimerization of the iCasp9 construct, both in vitro as well as in vivo.

$\mathrm{Bax} / \mathrm{Bak}$ are not required for apoptosis induction by dimerization of iCasp9 and this is not surprising as caspase-9 acts downstream of the mitochondria. Although several feed-forward amplification loops have been described between the intrinsic and extrinsic apoptosis pathway [28-30], the induction by iCasp9 is not dependent on this. So, loss of pro-apoptotic proteins can not block the effect of dimerization of iCasp9, making a very efficient tool for inducing apoptosis in chemotherapy-resistant cells.

Also, the dimerization of iCasp9 in vivo is able to target tumor cells and reduce tumor growth. The amount and frequency of treatment with the dimerizer does influence the effect, probably because the efficacy of the delivery is determined by this. A potential problem is that the construct can be inactivated or lost by the cells when they are pressure by treatment with the dimerizer. On the other hand, multiple dimerizer treatments in mice having a growing xenograft severely affected tumor growth at the long term. Additionally, intervention treatment showed that outgrowth of the tumor was almost completely abolished by dimerizer treatment, indicating that CSCs can be efficiently targeted by this treatment in vivo.

As mentioned previously, CSCs are resistant to conventional chemotherapy like 5-FU and oxaliplatin $[3,5]$. In agreement, recent findings confirm the selective resistance of CSC using the ABC transporter ABCB5 (Wilson). Here, we use this knowledge and confirm that that CSCs, marked by high CD133 expression, are resistant to 5-FU, whereas they are not to dimerization of iCasp9. This suggests that CSCs are probably not completely resistant to all drugs and this resistance can be overcome by efficient induction of cell death downstream in the apoptosis pathway. As the dimerization of iCasp9 efficiently targets CSCs, their resistance mechanism is probably more upstream in the apoptosis pathway. Potentially, CSCs have blocked the apoptosis induction at the level of the mitochondria. Interestingly, in vitro treatment of breast CSCs with compounds that target the mitochondria induces efficient killing of these cells [31]. It would be interesting to determine whether the resistance to upstream stimulation of the apoptotic pathways and the here described sensitivity to downstream pathway activation is also observed in primary samples derived from patients with cancer. In the past we have shown that also in freshly isolated tumor cells selective resistance to chemotherapy is apparent. However, whether these cells are sensitive to casp-9 dimerization remains to be established. Alternatively, additional experiments using drugs that activate downstream molecules in the apoptosis pathway could therefore be very informative for studying resistance in CSCs.

Because CSCs do not display any resistance to dimerization of iCasp9, this construct is a potential valuable tool for studying the role of CSCs in a growing tumor. It has been suggested that CSCs drive tumor growth and metastasis, but this has not been convincingly proven in in vivo experiments. Current experiments show that selection for expression of specific markers can identify the human tumor fraction that is able to xenograft in immunodeficient mice. These experiments mainly show that CSCs can initiate tumor growth upon transfer, which could reflect enhanced adherence, survival or growth in a foreign environment, but the necessity of CSCs to maintain tumor growth is unclear. Previously, circumstantial evidence for the role of CSCs in a growing tumor has been acquired by performing in vivo experiments to target 

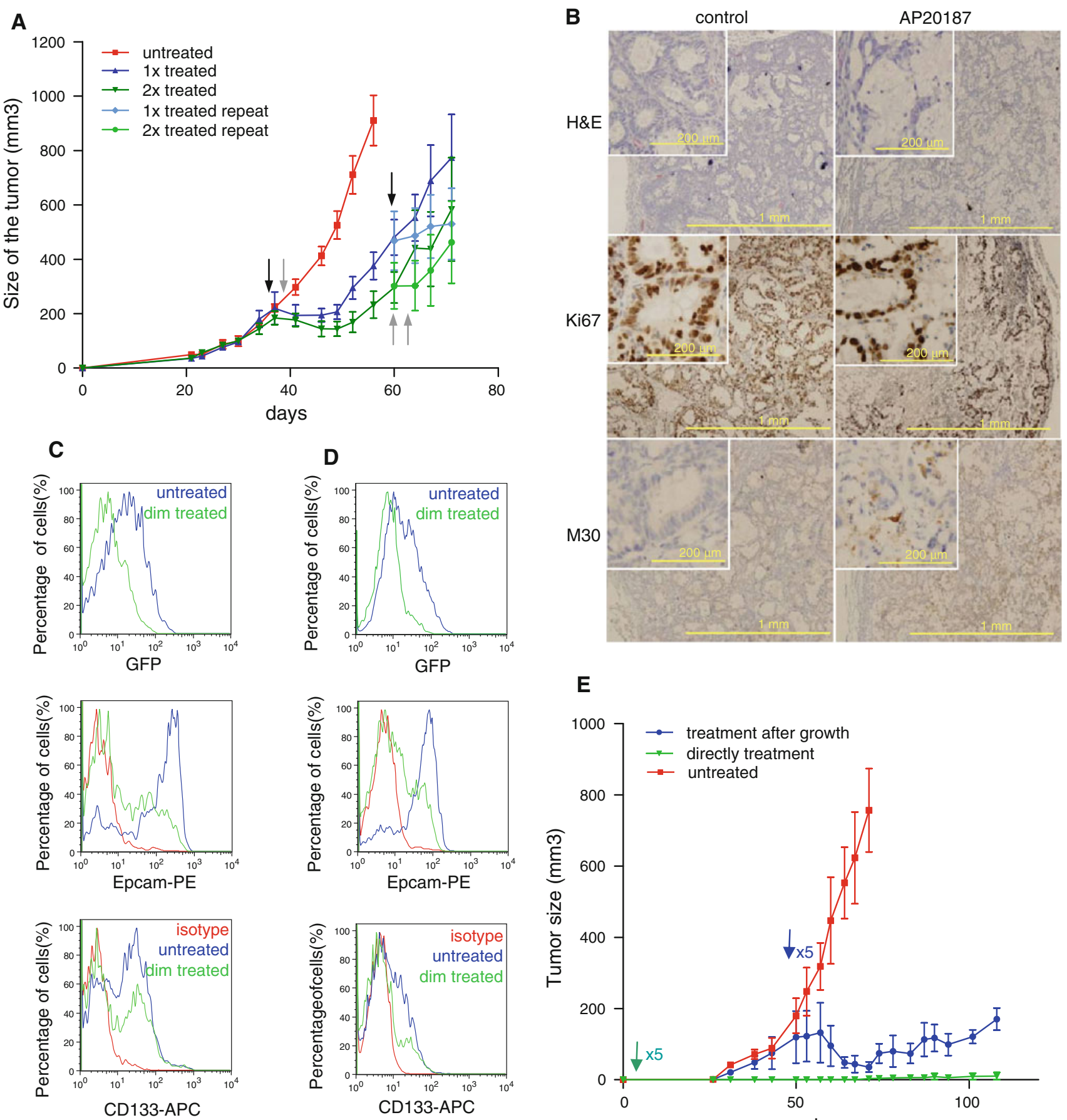

$\mathbf{F}$
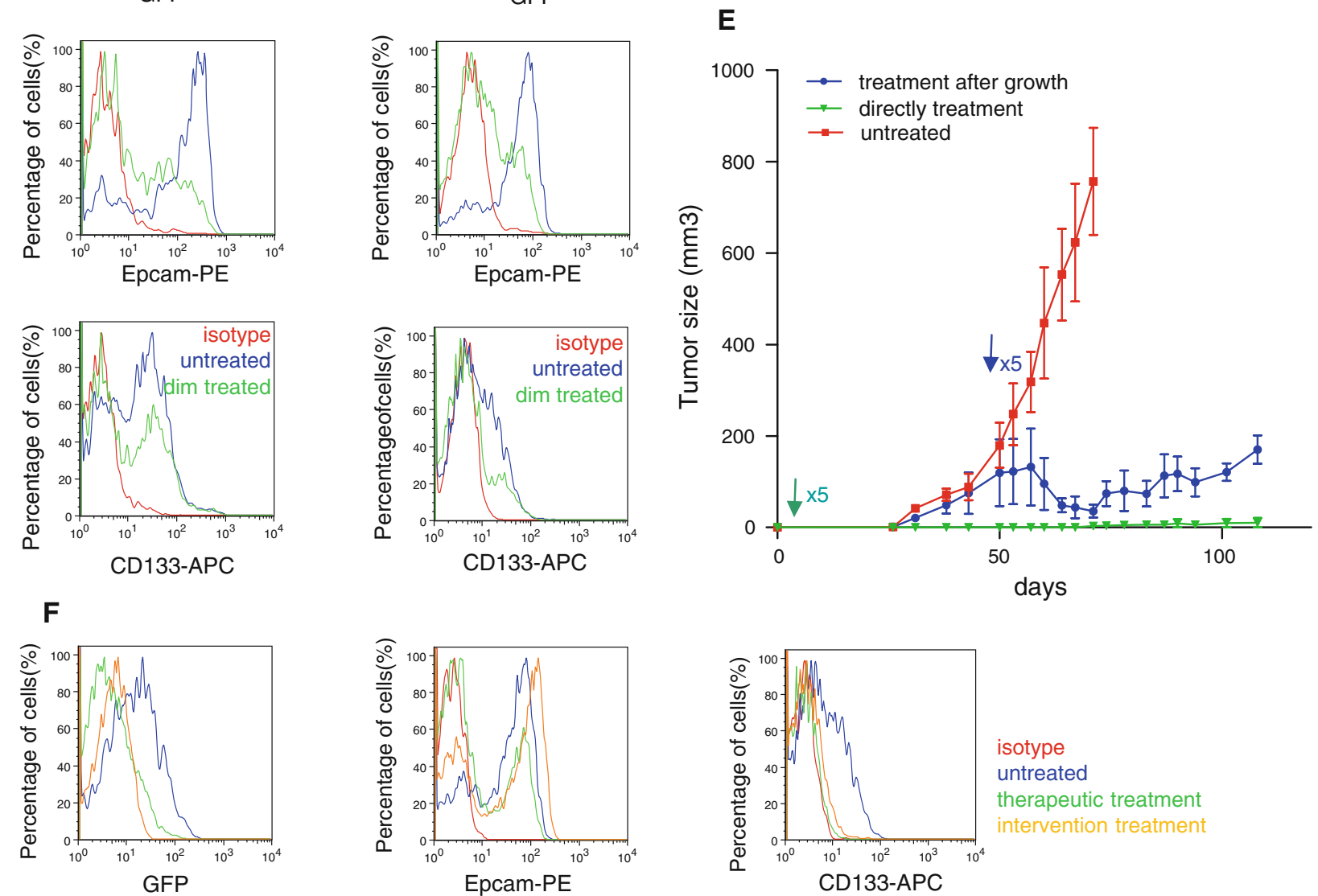

isotype

untreated

therapeutic treatment

intervention treatment 
4 Fig. 3 Dimerization of inducible caspase-9 induces apoptosis in vivo. A colon spheroid culture transduced with pMX-iCasp9-IRESGFP was injected subcutaneously in Balb/c nude mice. a Tumors were grown until $200 \mathrm{~mm}^{3}$ before the mice were treated either once or twice with $1 \mathrm{mg} / \mathrm{kg}$ dimerizer AP20187. One group was left untreated. After treatment, the tumors regressed but re-growth occurred rapidly, after which the half of the group was retreated again. The arrows indicate the time point of treatment. b Tumors were removed $48 \mathrm{~h}$ after the last treatment, embedded in paraffin and cut into slides. H\&E, Ki67 and cytodeath M30 staining showed that cell death occurs in the treated tumors, but still, living proliferating cells are present. c, d FACS analysis of these tumors show that treatment reduces both the $\mathrm{GFP}^{+}$and $\mathrm{Epcam}^{+}$and $\mathrm{CD}_{133^{+}}$fraction of the tumors cells, although Epcam ${ }^{+} \mathrm{CD} 133^{+}$cells are still present, both in tumors that were treated once (c) or twice (d). e Spheroid cells transduced with pMX-iCasp9-IRES-GFP were injected subcutaneously in nude mice and treated either directly after cell injection or after the tumors reached $200 \mathrm{~mm}^{3}$ for 5 days with $1 \mathrm{mg} / \mathrm{kg}$ dimerizer. The arrows indicate the start time point of treatment. f FACS analysis of tumors after outgrowth, analyzing GFP, Epcam and CD133 expression

CSCs in xenografts. For instance, when CRC xenografts were treated with an antibody against delta-like 4 ligand (DLL4), a ligand for the Notch signalling pathway, the tumor growth slowed down. In addition, this antibody treatment reduced stem cell frequencies, although only by two-fold, indicating that not all CSCs were targeted [32]. A similar approach was used in a melanoma xenograft model, in which CSCs can be identified by ABCB5 expression. Melanoma xenografts, treated with an antibody against ABCB5, which can induce antibody-dependent cell-mediated toxicity, showed a clear reduction in tumor growth [33]. Although this provides support for the idea that CSC are required for tumor growth, it is not clear whether the cytotoxic effect of the antibody treatment is unique to the CSCs or results in bystander kill. In the current in vivo experiments using dimerization of iCasp9 we observe a highly effective induction of apoptosis. This is observed in all tumor cells, but not in the stromal compartment. This therefore proves our hypothesis that selective ablation is possible. Future experiments will therefore have to be directed to CSC-specific expression of the iCasp9 construct, which would allow a timed and selective ablation of the CSC within a tumor and would provide valuable information on the role of these cells in growing tumors as compared to their role in xenograft initiation.

In conclusion, dimerization of iCasp9 induces rapid and efficient cell death, even in cancer cells that are normally resistant to conventional therapy due to overexpression of anti-apoptotic molecules or loss of pro-apoptotic molecules. Therefore, this construct is an interesting tool to study the effect of apoptosis of CSCs in a tumor model.

Acknowledgements Kristel Kemper was supported by a scholarship of the AMC Graduate School; Jan Paul Medema was supported by an NWO VICI grant and by a Dutch Cancer Society grant (UvA2009-4416).

Conflict of interest The authors declare that they have no conflict of interest.

Open Access This article is distributed under the terms of the Creative Commons Attribution Noncommercial License which permits any noncommercial use, distribution, and reproduction in any medium, provided the original author(s) and source are credited.

\section{References}

1. O'Brien CA, Pollett A, Gallinger S, Dick JE (2007) A human colon cancer cell capable of initiating tumour growth in immunodeficient mice. Nature 445:106-110

2. Ricci-Vitiani L, Lombardi DG, Pilozzi E, Biffoni M, Todaro M, Peschle C, De Maria R (2007) Identification and expansion of human colon-cancer-initiating cells. Nature 445:111-115

3. Todaro M, Alea MP, Di Stefano AB, Cammareri P, Vermeulen L, Iovino F, Tripodo C, Russo A, Gulotta G, Medema JP, Stassi G (2007) Colon cancer stem cells dictate tumor growth and resist cell death by production of interleukin-4. Cell Stem Cell 1:389-402

4. Vermeulen L, Todaro M, de Sousa MF, Sprick MR, Kemper K, Perez AM, Richel DJ, Stassi G, Medema JP (2008) Single-cell cloning of colon cancer stem cells reveals a multi-lineage differentiation capacity. Proc Natl Acad Sci USA 105:13427-13432

5. Cammareri P, Scopelliti A, Todaro M, Eterno V, Francescangeli F, Moyer MP, Agrusa A, Dieli F, Zeuner A, Stassi G (2010) Aurora-a is essential for the tumorigenic capacity and chemoresistance of colorectal cancer stem cells. Cancer Res 70:4655-4665

6. de Bruin EC, Mederna JP (2008) Apoptosis and non-apoptotic deaths in cancer development and treatment response. Cancer Treat Rev 34:737-749

7. Hanahan D, Weinberg RA (2011) Hallmarks of cancer: the next generation. Cell 144:646-674

8. Watson AJM, Merritt AJ, Jones LS, Askew JN, Anderson E, Becciolini A, Balzi M, Potten CS, Hickman JA (1996) Evidence for reciprocity of $\mathrm{Bcl}-2$ and $\mathrm{p} 53$ expression in human colorectal adenomas and carcinomas. Br J Cancer 73:889-895

9. Krajewska M, Moss SF, Krajewski S, Song K, Holt PR, Reed JC (1996) Elevated expression of Bcl-X and reduced Bak in primary colorectal adenocarcinomas. Cancer Res 56:2422-2427

10. Violette S, Poulain L, Dussaulx E, Pepin D, Faussat AM, Chambaz J, Lacorte JM, Staedel C, Lesuffleur T (2002) Resistance of colon cancer cells to long-term 5-fluorouracil exposure is correlated to the relative level of $\mathrm{Bcl}-2$ and $\mathrm{Bcl}-\mathrm{x}(\mathrm{L})$ in addition to Bax and p53 status. Int J Cancer 98:498-504

11. Fernandez-Peralta AM, Nejda N, Oliart S, Medina V, Azcoita MM, Gonzalez-Aguilera JJ (2005) Significance of mutations in TGFBR2 and BAX in neoplastic progression and patient outcome in sporadic colorectal tumors with high-frequency microsatellite instability. Cancer Genet Cytogenet 157:18-24

12. Fan LF, Freeman KW, Khan T, Pham E, Spencer DM (1999) Improved artificial death switches based on caspases and FADD. Hum Gene Ther 10:2273-2285

13. Dembinski JL, Krauss S (2009) Characterization and functional analysis of a slow cycling stem cell-like subpopulation in pancreas adenocarcinoma. Clin Exp Metastasis 26:611-623

14. Gao MQ, Choi YP, Kang S, Youn JH, Cho NH (2010) CD24(+) cells from hierarchically organized ovarian cancer are enriched in cancer stem cells. Oncogene 29:2672-2680 
15. Pece S, Tosoni D, Confalonieri S, Mazzarol G, Vecchi M, Ronzoni S, Bernard L, Viale G, Pelicci PG, Di Fiore PP (2010) Biological and molecular heterogeneity of breast cancers correlates with their cancer stem cell content. Cell 140:62-73

16. Roesch A, Fukunaga-Kalabis M, Schmidt EC, Zabierowski SE, Brafford PA, Vultur A, Basu D, Gimotty P, Vogt T, Herlyn M (2010) A temporarily distinct subpopulation of slow-cycling melanoma cells is required for continuous tumor growth. Cell 141:583-594

17. Xie XM, Zhao XQ, Liu YF, Zhang JF, Matusik RJ, Slawin KM, Spencer DM (2001) Adenovirus-mediated tissue-targeted expression of a caspase-9-based artificial death switch for the treatment of prostate cancer. Cancer Res 61:6795-6804

18. Hemmati PG, Guner D, Gillissen B, Wendt J, von Haefen C, Chinnadurai G, Dorken B, Daniel PT (2006) Bak functionally complements for loss of Bax during p14(ARF)-induced mitochondrial apoptosis in human cancer cells. Oncogene 25: 6582-6594

19. Zhang L, Yu J, Park BH, Kinzler KW, Vogelstein B (2000) Role of BAX in the apoptotic response to anticancer agents. Science 290:989

20. Cheng EHYA, Wei MC, Weiler S, Flavell RA, Mak TW, Lindsten T, Korsmeyer SJ (2001) BCL-2, BCL-X-L sequester BH3 domain-only molecules preventing BAX- and BAK-mediated mitochondrial apoptosis. Mol Cell 8:705-711

21. Wang XD (2001) The expanding role of mitochondria in apoptosis. Genes Dev 15:2922-2933

22. Zong WX, Lindsten T, Ross AJ, MacGregor GR, Thompson CB (2001) BH3-only proteins that bind pro-survival Bcl-2 family members fail to induce apoptosis in the absence of Bax and Bak. Genes Dev 15:1481-1486

23. Knudson CM, Tung KSK, Tourtellotte WG, Brown GAJ, Korsmeyer SJ (1995) Bax-deficient mice with lymphoid hyperplasia and male germ-cell death. Science 270:96-99

24. Lindsten T, Ross AJ, King A, Zong WX, Rathmell JC, Shiels HA, Ulrich E, Waymire KG, Mahar P, Frauwirth K, Chen Y, Wei M, Eng VM, Adelman DM, Simon MC, Ma A, Golden JA, Evan G, Korsmeyer SJ, MacGregor GR, Thompson CB (2000) The combined functions of proapoptotic Bcl-2 family members Bak and Bax are essential for normal development of multiple tissues. Mol Cell 6:1389-1399
25. Wei MC, Zong WX, Cheng EHY, Lindsten T, Panoutsakopoulou V, Ross AJ, Roth KA, MacCregor GR, Thompson CB, Korsmeyer SJ (2001) Proapoptotic BAX and BAK: a requisite gateway to mitochondrial dysfunction and death. Science 292: $727-730$

26. Vermeulen L, Melo FDSE, van der Heijden M, Cameron K, de Jong JH, Borovski T, Tuynman JB, Todaro M, Merz C, Rodermond H, Sprick MR, Kemper K, Richel DJ, Stassi G, Medema JP (2010) Wnt activity defines colon cancer stem cells and is regulated by the microenvironment. Nat Cell Biol 12:468-476

27. Li XX, Lewis MT, Huang J, Gutierrez C, Osborne CK, Wu MF, Hilsenbeck SG, Pavlick A, Zhang XM, Chamness GC, Wong H, Rosen J, Chang JC (2008) Intrinsic resistance of tumorigenic breast cancer cells to chemotherapy. J Natl Cancer Inst 100: 672-679

28. Fujita E, Egashira J, Urase K, Kuida K, Momoi T (2001) Caspase- 9 processing by caspase- 3 via a feedback amplification loop in vivo. Cell Death Differ 8:335-344

29. Fulda S, Meyer E, Friesen C, Susin SA, Kroemer G, Debatin KM (2001) Cell type specific involvement of death receptor and mitochondrial pathways in drug-induced apoptosis. Oncogene 20: 1063-1075

30. Scaffidi C, Fulda S, Srinivasan A, Friesen C, Li F, Tomaselli KJ, Debatin KM, Krammer PH, Peter ME (1998) Two CD95 (APO-1/ Fas) signaling pathways. EMBO J 17:1675-1687

31. Fischer M, Yen WC, Kapoun AM, Wang M, O'Young G, Lewicki J, Gurney A, Hoey T (2011) Anti-dll4 inhibits growth and reduces tumor-initiating cell frequency in colorectal tumors with oncogenic KRAS mutations. Cancer Res 71:1520-1525

32. Schatton T, Murphy GF, Frank NY, Yamaura K, Waaga-Gasser AM, Gasser M, Zhan Q, Jordan S, Duncan LM, Weishaupt C, Fuhlbrigge RC, Kupper TS, Sayegh MH, Frank MH (2008) Identification of cells initiating human melanomas. Nature 451: 345-349

33. Zobalova R, Prokopova K, Stantic M, Stapelberg M, Dong LF, Ralph SJ, Akporiaye E, Neuzil J (2011) The potential role of CD133 in immune surveillance and apoptosis: a mitochondrial connection? Antioxid Redox Signal 15(12):2989-3002 